\title{
Evaluation of Collaborative Enterprises Networks: Case Study of Brazilian Virtual Enterprises
}

\author{
Antonio José Cauliraux Pithon, Alessandro Garcia de Castro, \\ Paulo Enrique Stecklow, and Ralfh Varges Ansuattigui \\ CEFET-RJ \\ \{caulliraux, garciadecastro, paulo.stecklow\}@gmail.com, \\ varges@globo.com
}

\begin{abstract}
The emergency of the so called new digital economy, with intense diffusion of the information and telecommunication technologies, has provoked a revolution in the business world through the last years, changing the companies' paths and strategies, despite the nature of its products, markets and processes. Thus, the organizational networks become an alternative way of organizing the production of goods and services and may be used by the companies to improve its competitive position. This article's objective is to show the concept of virtual enterprises as dynamic collaborative networks by presenting some cases in other countries, to study the collaborative networks behavior and to compare the experience of foreign virtual companies with some Brazilian ones.
\end{abstract}

\section{Introduction}

The collaborative networks consist of a variety of entities (for instance, organizations and people) that are widely autonomous in terms of operating environment, organizational culture, social capital and goals. Nevertheless, these entities collaborate to achieve better objectives and goals, whose interactions are supported through computer networks [1].

The process of framing companies under pre-established perspectives demand a preliminary planning, focused on what is intended from the classification of these companies, whatever nature they are. This article qualifies virtual enterprises under criteria defined by students of the discipline Collaborative Networks taught in CEFET-RJ (Celso Suckow da Fonseca Technologic Educational Federal Center) in the first semester of 2009 , following a preliminary planning.

\subsection{Concept}

For a better understanding on the concept, we may see how some authors defined Collaborative Networks. According to Olivieri [2] "Networks are organizational systems capable of putting individuals and institutions together, in a democratic and participatory manner, around common goals and/or themes. Flexible structures, the networks are set up by horizontal relationships, dynamically interconnected, 
foreseeing the collaborative and participatory work. The networks are supported by its members will and affinity, characterized as a meaningful organizational resource for personal relationships as well as to social structuring".

Castells [3] states that "networks are the new social morphology of our societies, and the diffusion of networking logic substantially changes the operation and performance of productive processes, of experience, power and culture. Although the form of social organization in networks existed in other times and spaces, the new paradigm of information technology (IT) provides the material basis for its pervasive expansion throughout the social structure. Moreover, it can be said that this logic of networks generates a social determination at a higher level than the specific social interests expressed through networks: the power of the flows is more important than the flows of power".

According to the above concepts, we understand that Collaborative Networks are a set of bodies that connect to each other with common goals and affinities in an open system in constant interaction.

\subsection{Methodology}

The methodology adopted in this work was based on literature review in order to contextualize criteria to the qualifying of virtual enterprises. The survey-listed companies of all kinds of business, and the selection criteria was that each of them should be mandatorily a virtual enterprise and, also, their information would be investigated in the World Wide Web (WWW). Thus, six enterprises of different sizes were chosen and the analyzed period started from March up to June 2009.

The virtual enterprises listed in the survey were classified by their adherence to the chosen evaluation criteria. Each criterion was developed to classify the virtual enterprise on a scale of HIGH (H), MEDIUM (M) and LOW (L) and theirs criteria definitions is described ahead.

\section{Virtual Enterprise}

Virtual Enterprises (VE) are seen as an innovative form of management, a new model created to meet the expectations of an increasingly demanding and competitive market. Mowshowitz [4] first presented the concept of virtual enterprise in 1986 and, as joint ventures, virtual enterprises were created based on the theory of cooperation, as dynamic networks of companies.

There is not a consensus in the literature about the concept of virtual enterprise, but the ones that meet most of the concepts for this work agreed that VE consist in a temporary network of independent companies - suppliers, customers, even competitors - linked by IT to share skills, costs and to allow common access to their same markets [4]. Fuehrer [5] considers a VE a temporary network of independent institutions, businesses or specialized individuals, working together in a spontaneous way through TI in order to achieve a gain in a demanding competitive market, as well as Travica [5] affirms that VE is a new organizational form characterized by temporary or permanent grouping of geographically dispersed individuals, groups or organizational departments not belonging to the same organization, which are dependent on IT to maintain their production processes. 
Exploring these definitions we can assume some VE features, like "temporality", that means that It is created to last only the necessary time to meet a specific demand (However, there is no impediment as to its perpetuation and structure reconfigurations), "meeting skills" by improving the synergy among network agents, massive use of IT, "Cooperation" among members in a synchronous or asynchronous way and "confidence" based on the mutual confidence between the members to allow the best accomplishment of the work.

\section{Case Study}

Based on literature review, some criteria have been developed in this study to evaluate companies. They are Sustainability, Communicability, Flexibility, Coverage, Correctness, Stability, Awareness And Technological Infrastructure. Each criterion is defined as follows:

\subsection{Sustainability}

According to the United Nations Organization (UN) sustainability is defined as "meeting the needs of present generations without compromising the ability of meeting the needs of future generations" [6]. Sustainability means survival of natural resources, enterprises and the society itself. It is based on the so-called Triple Bottom Line, consisting of three pillars: economic, social and environmental. This means that for any development survives, it will have to be socially fair, environmentally responsible and economically profitable. Thus, to promote the continuity of business, these three components should be necessarily present [7].

As the sustainability rating in this study, the scoring of certain criteria indicates the degree of sustainability of the considered companies. Each criterion evaluates to 2 points when it clearly applies to a company, one point when it applies but with a lesser degree of strength and zero point when it does not apply. The criteria to measure sustainability are customer loyalty marketing strategy, corporate image and brand enrichment, crisis management and public opinion control, scored accordingly to the score set in the Table 1.

Table 1. Sustainability level score classification ( $\mathrm{H}$ - High, $\mathrm{M}$ - Medium and L - Low)

\begin{tabular}{|c|c|c|}
\hline \multicolumn{3}{|c|}{ Sustainability Level Score Classification } \\
\hline $0-2 \rightarrow \mathrm{L}$ & $3-5 \rightarrow \mathrm{M}$ & $6-8 \rightarrow \mathrm{H}$ \\
\hline
\end{tabular}

\subsection{Communicability}

Communicability is the quality of the optimized communicative act, in which the message is fully, accurately, quickly and economically delivered. The integral transmission assumes that there are not suppressive, distorting or concurrent noises. The correct transmission implies identity between the message delivered by the sender and the received one by the receiver. The speed assumes that the message 
follows by the shortest way. The economy assumes that returns, efforts to decode and understand are not necessary.

Virtual communicability can be defined as the possibility of anyone using any kind of communication access (graphical browsers, textual, special for the blind or for mobile computing systems) to getting a complete understanding of the information contained in it, beyond having full and complete ease to interact with it. Thus, the communicability proposed refers to the possibility of the virtual space being accessed by anyone, regardless of situation, limitations or applied tool.

For qualifying the virtual enterprise in the context of communicability we considered the quality of oral communication optimized for pronounceability, audibility, readability, processability and accessibility, by summing the score applied to every criteria (Table 2).

Table 2. Sustainability level score classification ( $\mathrm{H}$ - High, $\mathrm{M}$ - Medium and L - Low)

\begin{tabular}{|c|c|c|}
\hline \multicolumn{3}{|c|}{ Communicability Level Score Classification } \\
\hline $0-3 \rightarrow \mathrm{L}$ & $4-7 \rightarrow \mathrm{M}$ & $8-10 \rightarrow \mathrm{H}$ \\
\hline
\end{tabular}

\subsection{Flexibility}

Considering flexibility as a set of features that allow an enterprise to face unplanned situations [8], it is easy to see that some capabilities enable the company to deal with variations in demand for its products.

Indicators for assessing a virtual enterprise for flexibility are plan of positions consistent with the work activities, providing training courses in the business, access to quality internet, human resources policies and availability of software tools and hardware. Each criterion evaluates to 3 points when it applies in a formal and efficient way, two points when it applies informally and one point when it does not apply. Considering the score of each indicator, the enterprise can obtain a final score ranging from five to fifteen, qualifying it for flexibility (Table 3).

Table 3. Flexibility level score classification ( $\mathrm{H}$ - High, $\mathrm{M}$ - Medium and L - Low)

\begin{tabular}{|c|c|c|}
\hline \multicolumn{3}{|c|}{ Flexibility Level Score Classification } \\
\hline $5-7 \rightarrow \mathrm{L}$ & $8-11 \rightarrow \mathrm{M}$ & $12-15 \rightarrow \mathrm{H}$ \\
\hline
\end{tabular}

\subsection{Coverage}

The use of IT, according to [9], allows the cooperation established between the partners in a virtual organization to assume a global dimension, exceeding the limits of time and distance between the corporation and its customers as a strategic way of increasing competitiveness and coverage.

The coverage as an attribute of a virtual organization has the meaning of range or maximum reachable geographical limit of operation and this can be dynamic to the extent of the variations in the resulting logistics due to organization and type of product or service offered, scored as follows (Table 4): 
Table 4. Coverage Level Score Classification ( $\mathrm{H}$ - High, $\mathrm{M}$ - Medium and L - Low)

\begin{tabular}{|c|c|c|c|c|c|}
\hline \multicolumn{6}{|c|}{ Coverage Level Score Classification } \\
\hline $\begin{array}{c}\text { Local coverage } \\
\text { (city/state) }\end{array}$ & $\rightarrow \mathrm{L}$ & $\begin{array}{l}\text { National } \\
\text { coverage }\end{array}$ & $\rightarrow \mathrm{M}$ & $\begin{array}{c}\text { International } \\
\text { coverage }\end{array}$ & $\rightarrow \mathrm{H}$ \\
\hline
\end{tabular}

\subsection{Correctness}

Correctness refers to the quality of management, characterized by inter-elements processes that support the sharing, integration and access to resources necessary to achieve their goals. The degree of importance to this criterion is established as Low (lack of or without business processes of any kind), Medium (a combined arrangement of formal with non-formal business processes) and High (formal business processes fully spread among the VE).

\subsection{Stability}

This criterion is based on the financial stability, characterized by the rational use of financial resources that support the production system. The liquidity attempts to measure the stability of the financial foundations of the company [10]. We consider stability as the property of maintenance and regulation of aggregation and dynamic balance of the networked organization, by means of internal mechanisms.

Based on programs and projects performance scores lead by the networked organization, the stability was classified as High (it is fully perceived), Medium (it is moderately perceived) and Low (there is no relevant perception of stability).

\subsection{Awareness}

According to [11], the awareness by consumers can be tangible (are those easily measurable) and intangible (have the task of showing the customer that the company is unique). This work proceed to the analysis of the criterion based on the analysis model [12], to assess customer satisfaction. So it is considered as the dependent variable for this analysis the perceived degree of satisfaction of customers, based on the overall perceived user satisfaction, content relevance of the system, speed of the system, format of the system, usability of the system and timeliness of the system.

The evaluation of the criterion was made by scoring the sub-groups of the variables described above, assigning two points when the criterion is identifiable and expressed in a formal way, one point when there is no strength at the observation of the criterion and zero point when the criterion is not observed at all (Table 5).

Table 5. Awareness Level Score Classification ( $\mathrm{H}$ - High, $\mathrm{M}$ - Medium and L - Low)

\begin{tabular}{|c|c|c|}
\hline \multicolumn{3}{|c|}{ Awareness Level Score Classification } \\
\hline $0-3 \rightarrow \mathrm{L}$ & $4-9 \rightarrow \mathrm{M}$ & $10-12 \rightarrow \mathrm{H}$ \\
\hline
\end{tabular}




\subsection{Technological Infrastructure}

Infrastructures operate as the basis on which things are added in order to generate value, production or service. Karl Marx, in 1847, said that the social forces are linked to the productive forces, which in turn, change the social relations [13], has conceptualized these infrastructures.

From the 1960's, with technology previously driven by the Second World War, new management theories emerging and with industrialization almost like we know today, the concept of infrastructure started to be employed in matters hardware infrastructure. This designation, when expressed by means of computing infrastructure weakens the semantic definition of infrastructure, which now does not express only hardware but also software, standards and procedures [14].

An adapted model choice of methods and techniques for evaluating information systems [15] and [16] was used, and because of lacking of available enterprises information, was considered only the context of programmed decisions, in which are represented by the repetitive and ordinary decisions and that do not require a different treatment for each time they occur, whereas non-programmed decisions require a more invasive approach to the organizations studied.

Custodio [15] represents the three levels of classification - "high", "medium" and "low" considering communication between groups, control of routines, project management and production planning. The total score is the result of the sum of the scores given to each of the four structured decisions listed above and adapted for this study (Table 6).

The structured decision is equivalent to the sum of their parts, which are worth 1 (one) point when they are identified within the virtual enterprise and 0 (zero) point if not observed in the virtual enterprise, resulting in the following rating scale:

Table 6. Technological Infrastructure Level Score Classification $(\mathrm{H}-\mathrm{High}, \mathrm{M}-\mathrm{Medium}$ and L - Low)

\begin{tabular}{|c|c|c|}
\hline \multicolumn{2}{|c|}{ Technological Infrastructure Level Score Classification } \\
\hline $0-3 \rightarrow \mathrm{L}$ & $4-8 \rightarrow \mathrm{M}$ & $9-12 \rightarrow \mathrm{H}$ \\
\hline
\end{tabular}

\section{Criteria versus Enterprise}

The six enterprises chosen to this study was Virfebrás [17], Cederj [18], Informaker [19], CVRD [20], Prodweb [21] and NOGI Fightwear [22] and will be shortly described above. Note that it was chosen a heterogeneous type of companies for this analysis, instead of narrowing the sample space of this study.

Virtual Organization of Tools of Brazil - VIRFEBRAS - is a group of companies of tooling organized as a cooperative in the production of die and mold, where each of them maintains its own identity. Distance Learning Center on Higher Education CEDERJ is a consortium of public universities, created in 2000 by the Rio de Janeiro Government, with the explicit aim of promoting continuing education to university graduates, with special attention to upgrading teachers in the public high school. InforMaker is an Information Technology company, which operates in the IT market 
since 1988 in various segments of which we can highlight the Virtual Software Factory. Companhia Vale do Rio Doce - CVRD is one of the largest mining companies in the world, but to maintain its leadership position has been forming alliances and networks with customers and suppliers to further strengthen their trade relations. Prodweb is a virtual enterprise that provides software solutions (websites development, e-commerce and systems development) and operates under a model based on the network integration with its clients, thus achieving the optimization of targets and deadlines to meet. NO GI Fightwear is a manufacturer of clothing and accessories for martial arts practice, that operates in domestic and international markets. Its production process is based on a strong alliance with suppliers and garments, integrated through IT.

Table 7 shows the classification of companies based on criteria developed. The classification of HIGH, MEDIUM and LOW represents the analysis of each criterion, based on specific rules for each one of them.

Table 7. Enterprise Classification versus criteria (H - High, $\mathrm{M}$ - Medium and L - Low)

\begin{tabular}{|l|c|c|c|c|c|c|}
\cline { 2 - 7 } \multicolumn{1}{c|}{} & Virfebrás & Cederj & Informaker & CVRD & Prodweb & $\begin{array}{r}\text { NOGI } \\
\text { Fightwear }\end{array}$ \\
\hline Sustainability & $\mathrm{H}$ & $\mathrm{H}$ & $\mathrm{H}$ & $\mathrm{H}$ & $\mathrm{M}$ & $\mathrm{H}$ \\
\hline Communicability & $\mathrm{H}$ & $\mathrm{H}$ & $\mathrm{H}$ & $\mathrm{H}$ & $\mathrm{M}$ & $\mathrm{H}$ \\
\hline Flexibility & $\mathrm{H}$ & $\mathrm{M}$ & $\mathrm{H}$ & $\mathrm{H}$ & $\mathrm{H}$ & $\mathrm{M}$ \\
\hline Coverage & $\mathrm{M}$ & $\mathrm{L}$ & $\mathrm{M}$ & $\mathrm{H}$ & $\mathrm{H}$ & $\mathrm{H}$ \\
\hline Correctness & $\mathrm{L}$ & $\mathrm{H}$ & $\mathrm{H}$ & $\mathrm{H}$ & $\mathrm{M}$ & $\mathrm{M}$ \\
\hline Stability & $\mathrm{H}$ & $\mathrm{H}$ & $\mathrm{M}$ & $\mathrm{H}$ & $\mathrm{H}$ & $\mathrm{L}$ \\
\hline Awareness & $\mathrm{M}$ & $\mathrm{H}$ & $\mathrm{M}$ & $\mathrm{H}$ & $\mathrm{H}$ & $\mathrm{M}$ \\
\hline Infrastructure & $\mathrm{M}$ & $\mathrm{M}$ & $\mathrm{M}$ & $\mathrm{H}$ & $\mathrm{L}$ & $\mathrm{M}$ \\
\hline
\end{tabular}

Considering that as much " $\mathrm{H}$ " given to a company, as much virtual it is, these companies can be classified according to the level of virtuality, from the more virtual to the less virtual as follows: CVRD, Cederj, Informaker, Virfebrás, Prodweb and NOGI Fightwear. These companies, when they are analyzed under the level of development and considering how formal the enterprises in the net are, the results are very similar, comparing with the virtuality level shown on Table 7.

\section{Conclusion}

The process of qualifying enterprises for selected parameters to evaluation of virtual enterprises in Brazil based on the concepts of the discipline of Collaborative Networks of The Master Course in Technology, CEFET-RJ has to be done with careful planning and by preliminarily establishing goals that this classification seeks. One of the biggest challenges of this work was to obtain data so that the qualification could be done in the most assertive way.

For a more accurate classification of the enterprises, it's necessary to establish mechanisms more focused on obtaining data such as interviews and questionnaires, prepared according to the need of the classification criteria. When the criteria for the 
studied enterprises are solely for virtual enterprises, the situation gets complicated: It is difficult to identify the character of "virtuality" of companies, because as the concept of "virtual company" is still elusive, with different definitions between authors, the company itself ends up complicating the access to data classification from the perspective of "virtual company".

Realized the difficulty of performing more complex activities in a network without hierarchy, which confirms the need to have a business articulator of virtual enterprise. It will not be stated that there is a need for a broker, since there is no systematic and definitive studies on the function and role of brokers in business networks.

The articulator is responsible for making the business processes of the network be followed, that goals are achieved without unnecessary redundant activities, maintaining the synergy between the actors of the network and taking a holistic approach that optimizes the network to achieve efficiency and pursue new opportunities.

\section{References}

1. Camarinha-Matos, L., Afsarmanesh, H.: Journal of Intelligent Manufacturing 1(Ed. 16), 439-452 (2005)

2. Olivieri, L.: A importância histórico-social das redes (2002)

3. Castells, M.: A sociedade em rede (A era da informação: economia, sociedade e cultura). Paz e Terra, São Paulo (1999)

4. Corrêa, G.: Proposta de Integração de parceiros na formação e gerência de Empresas Virtuais (Tese de Doutorado). Escola de Engenharia de São Carlos, Universidade de São Paulo - USP, São Paulo, Brasil (1999)

5. Pithon, A.: Projeto Organizacional para a Engenharia Concorrente no Âmbito das Empresas Virtuais, Minho, Portugal (2004)

6. ONU - Organização das Nações Unidas: Relatório Brundtland (1987)

7. Credidio, F.: Sustentabilidade - Você sabe o que significa essa palavra? In: SINPRORP, http: //www.sinprorp.org.br/Jornais/filantropia170.htm (accessed Outubro 2008)

8. Corrêa, H.L., Slack, N.: Flexibilidade estratégica na manufatura: incertezas e variabilidade de saídas. Revista de Administração 29 (1994)

9. Tröger, A.: Um Estudo Sobre Organizações Virtuais (1997)

10. Schvirck, E., Giasson, O.: Diferenças nos indicadores de desempenho de empresas que fazem e que não fazem reavaliação de ativos (2006)

11. Munhoz, C.: O Marketing de Relacionamento para Pequenas Empresas. In: Portal do Marketing, http: / / www . portaldomarketing . com.br/

Artigos / Marketing $\% 20$ de 20 Relacionamento\%2 0para 20 pequenas\% 20 empresas.htm (accessed 2003)

12. Senger, I.: Gestão de Sistemas de Informação Acadêmica: um estudo descritivo da satisfação dos usuários, Lavras (2005)

13. Marx, K.: Miséria da Filosofia. Centauro (2004)

14. Ambrosi, A., Pimienta, D., Peugeot, V.: Enjeux de mots: Regards multiculturels sur les sociétés de l'information. C \& F Éditions (2004)

15. Custódio, I.: Avaliação de Sistemas de Informação: um modelo para auxiliar na escolha de métodos e técnicas. Revista de Administração 18(4) (1983) 
16. Gorry, A., Morton, M.: A Framework for Management Information Systems. Alfred P. Sloan School of Management - Massachussets Institute of Technology (1971)

17. Virfebrás - Organização Virtual de Ferramentarias do Brasil, http: / / www. virfebras.com.br/

18. Governo do Rio de Janeiro - Secretaria de Ciência e Tecnologia: Fundação CECIERJ. In: Consórcio CEDERJ, http: / / www . cederj . edu.br / fundacaocecierj / exibe_artigo.php

19. InforMaker: Quem Somos. In: InforMaker, http: / / www. informaker. com. br/QuemSomos. asp

20. Tauhata, T., Macedo-Soares, D.: Redes e Alianças Estratégicas no Brasil: caso CVRD. RAE-eletrônica 3(1) (2004), http: / / www . rae.com.br/eletronica / index . $\mathrm{c}$ fm?FuseAction=Artigo\&ID=1811\&Secao=ESTRATGIA\& Volume $=3 \&$ Numero $=1 \& A$ Ano $=2004$

21. In: Prodweb - Soluções de Software para a Web, http : / / www . prodweb. com. br /

22. In: NO GI Fightwear web site, http://www.nogi.com.br/site-ptbr/index.php 